\title{
cross diffusion 項をもつ移流拡散方程式の安定性解析 STABILITY ANALYSIS CONVECTION-DIFFUSION EQUATION WITH CROSS DIFFUSION
}

\author{
平岡久司* \\ Hisashi HIRAOKA
}

This paper reports a way to compute Differential Stress Model stably. Differential Stress Model belongs a kind of convection-diffusion equation with cross diffusion term.: We showed how to determine a stable time step for an equation of this sort, based on the Hirt's heuristic stability analysis, with which a time step is calculated easily. The Hirt's method was supported by the Neumann's Fourier series analysis.

Keywords : stability analysis, differential stress model, cross diffusion, Hirt's method, Neumann's method

安定性解析, 応力方程式モデル, cross diffusion, Hirt の方法, Neumann の方法

\section{1. 緒 言}

この研究の目的は, cross diffusion 項をもつ移流拡散 方程式の安定性解析をHirt の heuristic（発見的）な方 法により行うことである。

応力方程式モデルをMAC 法のような非定常計算法 で解く場合, 安定性解析によりタイムステップを決める 必要がある。このような安定性解析では Neumann の フーリ工級数法が理論的ではあるが，2 次元，3 次元場 では夕イムステップを解析的に求めることが困難にな る。数値的に求めることも過大な計算量が必要になる。 一方, Hirt の安定性解析は理論的ではないが, タイム ズテップの決定が容易である。Hirt の安定性解析を用 いて比較的簡単に安定なタイムステップを求めることが できれば，実際の数值計算に役立つ。また，応力方程式 モデル（ここでは IPM を採用する゙)）の基本的な方程 式型は, cross diffusion 項をもつ移流拡散方程式である。 このような方程式の安定性解析はまだ研究されていな い。本研究では応力方程式モデルを解くために，このよ うな cross diffusion 項をもつ移流拡散方程式の安定性 解析をHirt の方法により行い, 安定なタイムステップ を求める方法について考察する。

MAC 法のような非定常陽解法で計算するとき, 夕イ ムステップを大きく取ると計算が不安定になり発散して しまう。ある値以下のタイムステップでは計算は安定に なり収束する。このようなタイムステップを安定性解析
により決定することは，計算効率を高めることになり， 短い cpu タイムで計算を収束させる利点をもつ。本研 究ではこのような安定性を保証するタイムステップの決 定方法について考察を行う。また，この研究では低メッ シュ Re 数をも含めたすべてのメッシュ Re 数での安定 性解析を行った。その理由は, 風洞実験や模型実験では 乱れがコントロールされており, 比較的小さい乱流強度 になっているため, 移流支配型の安定性解析から決定さ れたタイムステップのみを用いても計算は収束するが, 実際の自然風なよ゙のように乱流強度が大きい場合には拡 散支配型（熱伝導型）の安定性解析から決定された夕イ ムステップによって流れ場全体のタイムステップが決定 されることがしばしば生じるためである。

\section{2. cross diffusion 項をもつ移流拡散方程式}

cross diffusion 項を持つ移流拡散方程式は次式で表わ さ机る。

$$
\frac{\partial \phi}{\partial t}+U_{j} \frac{\partial \phi}{\partial x_{j}}=\nu_{i j} \frac{\partial^{2} \phi}{\partial x_{i} \partial x_{j}}
$$

粘性マトリックスを次式で定義する。

$$
[\nu]=\left[\begin{array}{lll}
\nu_{11} & \nu_{12} & \nu_{13} \\
\nu_{12} & \nu_{22} & \nu_{23} \\
\nu_{13} & \nu_{23} & \nu_{33}
\end{array}\right]
$$

ここで，対称な粘性マトリックス $\left(\nu_{i j}\right)$ は正定値と仮 定する。この仮定は拡散項が棈円型（物理的に拡散性を

\footnotetext{
* 京都大学工学部環境地球工学科 助手. 工修
}

Research Assoc., Dept. of Global Environment Engineering, Faculty of Engineering, Kyoto Univ., M. Eng. 
示す)になるためのものであり（[Appendix-1] 参照)， また，安定性解析においては正のタイムステップが取れ るための条件でもある 方程式モデルでは， $\phi$ はレイノルズ応力, 粘性消散率を 表す。平均流の式に Huang らの pseudo-viscosity 表現 ${ }^{2)}$ を施せば， $\phi$ は平均流をも示す。

\section{2 次元移流拡散方程式の安定性解析}

3.1 Neumann のフーリ工級数法による安定性解析 以後の解析のために，粘性と流速を次のように表す。

$$
\begin{aligned}
& U_{1}=U, \quad U_{2}=\alpha U, \quad|\alpha| \leq 1 \cdots \cdots \cdots \cdots \cdots \cdots(3 \\
& \nu_{11}=\nu, \quad \nu_{22}=\gamma \nu, \quad \nu_{12}=\beta \sqrt{\gamma} \nu,|\beta|<1, \quad \gamma>0
\end{aligned}
$$

（1）式を時間微分に関して前進差分（タイムステッ プ $\Delta t$ ），空間微分に関して中心差分（格子幅 $h$ ）を取 れば，以下のような差分方程式になる。

$$
\begin{aligned}
& \frac{\phi_{i, j}^{n+1}-\phi_{i, j}^{n}}{\Delta t}+U_{1} \frac{\phi_{i+1, J}^{n}-\phi_{i-1, j}^{n}}{2 h}+U_{2} \frac{\phi_{i, j+1}^{n}-\phi_{i, J-1}^{n}}{2 h} \\
& =\nu_{11} \frac{\phi_{i+1, j}^{n}+\phi_{i-1, j}^{n}-2 \phi_{i, j}^{n}}{h^{2}}+\nu_{22} \frac{\phi_{i, j+1}^{n}+\phi_{i, j-1}^{n}-2 \phi_{i j}^{n}}{h^{2}} \\
& \quad+2 \nu_{12} \frac{\phi_{i+1, j+1}^{n}-\phi_{i+1, j-1}^{n}-\phi_{i-1, j+1}^{n}+\phi_{i-1, j-1}^{n}}{4 h^{2}}
\end{aligned}
$$

\subsection{Neumann の方法によるタイムステップの决定}

（5）式を Neumannのフーリ工級数法により安定性 解析を行えば，タイムステップ $\Delta t$ は次式で表される。

$$
\Delta t<\operatorname{cof}_{c N}(\alpha, \beta, \gamma, \operatorname{Re}) \frac{2 \nu}{U^{2}}=\operatorname{cof}_{a N}(\alpha, \beta, \gamma, \operatorname{Re}) \frac{h^{2}}{4 \nu}
$$

ただし，

$$
\begin{aligned}
& \operatorname{cof}_{c N}(\alpha, \beta, \gamma, \operatorname{Re}) \\
& =\min _{\substack{-\pi \leq \theta_{1} \leq \pi \\
-\pi \leq \theta_{2} \leq \pi}}\left\{\frac{2 a\left(\theta_{1}, \theta_{2}, \beta, \gamma\right)}{\frac{4}{\operatorname{Re}^{2}} a^{2}\left(\theta_{1}, \theta_{2}, \beta, \gamma\right)+\left(\sin \theta_{1}+\alpha \sin \theta_{2}\right)^{2}}\right\} \\
& \operatorname{cof}_{\mathrm{aN}}(\alpha, \beta, \gamma, \mathrm{Re}) \\
& =\min _{\substack{-\pi \leq \theta_{1} \leq \pi \\
-\pi \leq \theta_{2} \leq \pi}}\left\{\frac{16 a\left(\theta_{1}, \theta_{2}, \beta, \gamma\right)}{4 a^{2}\left(\theta_{1}, \theta_{2}, \beta, \gamma\right)+\operatorname{Re}^{2}\left(\sin \theta_{1}+\alpha \sin \theta_{2}\right)^{2}}\right\} \\
& a\left(\theta_{1}, \theta_{2}, \beta, \gamma\right)=1+\gamma-\left(\cos \theta_{1}+\gamma \cos \theta_{2}\right) \\
& +\beta \sqrt{\gamma} \sin \theta_{1} \sin \theta_{2} \\
& \operatorname{Re}=\frac{U h}{\nu}
\end{aligned}
$$

ここで,（6）式の右辺の表現を拡散型表現, 第 2 項 の表現を移流型表現と呼ぶことにする。（7），(8) 式 から明らかなように，フーリエ級数法による表現では夕 イムステップはメッシュ $\operatorname{Re}$ 数に依存する。（7)，(8) 式は解析的に導出するのが困難なため, 数値計算により 係数值を求めることにする。

\section{3 Hirt の安定性解析}

\section{3.1 移流型表現}

（5）式の第 1 微分方程式近似（たとえば, 文献1参照, 用語は文献6)に従った）は次式で表される。

$$
\frac{\partial \phi}{\partial t}+U_{j} \frac{\partial \phi}{\partial x_{j}}=\nu_{t j}^{e} \frac{\partial^{2} \phi}{\partial_{x_{l}} \partial x_{j}}
$$

ただし，

$$
\nu_{i j}^{e}=\nu_{i j}-\frac{\Delta t}{2} U_{i} U_{j}
$$

「(12) 式の実効粘性係数 $\nu_{i j}^{e}$ (用語は文献)に従った） によって作られる，実対称なマトリックスが正定值を取 ること」が Hirt の方法による安定性の条件 (文献)参照) である注1。タイムステップを求めると次式となる。

$$
\begin{aligned}
& \Delta t_{c H}<\frac{2\left[\nu_{11} \nu_{22}-\left(\nu_{12}\right)^{2}\right]}{\nu_{22} U_{1}^{2}+\nu_{11} U_{2}^{2}-2 \nu_{12} U_{1} U_{2}} \\
& =\operatorname{cof}_{c H}(\alpha, \beta, \gamma) \frac{2 \nu}{U^{2}} \cdots \ldots \ldots \ldots \ldots . . . \\
& \operatorname{cof} f_{c H}=\frac{\gamma\left(1-\beta^{2}\right)}{\gamma+\alpha^{2}-2 \alpha \beta \sqrt{\gamma}} \cdots \cdots \ldots . . .
\end{aligned}
$$

$\operatorname{Re}$ が十分大きい（ $\operatorname{Re}>7 ）$ ときの Neumann の移流型 表現 (( 7$)$ 式)と (14) 式を比較した図を図一1に示す。 Hirt の方法と Neumann の方法とは, Re が十分大きい とき一致するのがわかる（この結果は文献ででも示し た)。

\section{3.2 拡散型表現}

（5）式の第 1 微分方程式近似は次式でも表される（た とえば, 文献 ${ }^{1}$ 参照)。

$$
\frac{\Delta t}{2} \frac{\partial^{2} \phi}{\partial t^{2}}-\nu_{i j} \frac{\partial^{2} \phi}{\partial x_{t} \partial x_{j}}+\frac{\partial \phi}{\partial t}+U_{j} \frac{\partial \phi}{\partial x_{j}}=0 \cdots
$$

（15）式の下線部の波動方程式を考察する。Hirt の安 定性の条件は，「原点を基準として $\Delta t$ 後に，(15）式下 線部の波動方程式の特性錐（の断面）が差分格子の領域 内に入っていること」である [Appendix-2] 参照)。

差分格子の領域を，図一 2 に示す 9 点を含む, 正方形 (12341) とした場合 (cross diffusion 項を含んだ領域) の安定性の条件は次式になる ([Appendix-3] 参照)。

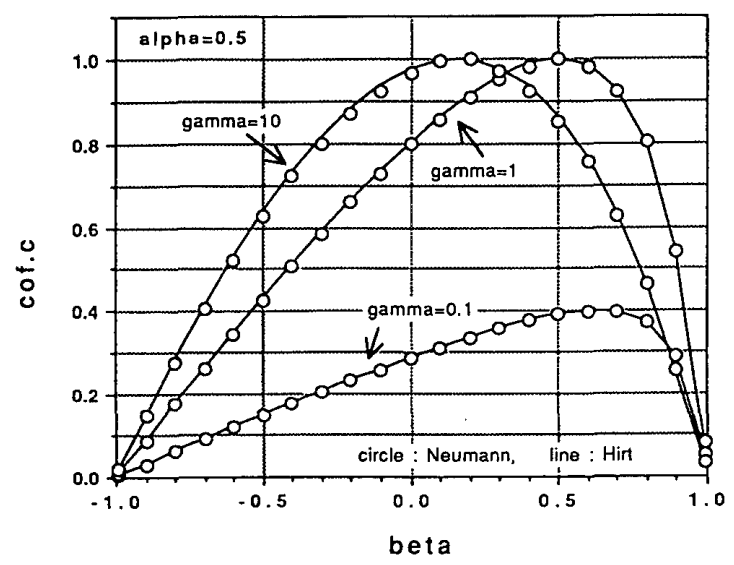

图一1２次元移流型表現（Hirt と Neumann の方法の結果） 


\section{（1） 9 点差分格子の場合}

$$
\Delta t_{d(9 \mathrm{iH})}<\operatorname{cof}_{d(9) \mathrm{H}} \frac{h^{2}}{4 \nu}
$$

ただし

$$
\operatorname{cof}_{d(9) H}=\min \left\{2, \frac{2}{\gamma}\right\}
$$

差分格子の領域を, 図一2に示す 5 点を含む，正方形 (ENWSE) とした場合 (diagonal diffusion 項のみを 含んだ領域), 安定性の条件は次式になる([Appendix-4] 参照)。

（2） 5 点差分格子の場合

$$
\Delta t_{d(5) H}<\frac{h^{2}}{2\left(\nu_{11}+\nu_{22}\right)}=\operatorname{cof} f_{d H} \frac{h^{2}}{4 \nu}
$$

ただし，

$$
\operatorname{cof} f_{d H}=\frac{2}{1+\gamma}
$$

$\operatorname{Re}$ が十分小さい $(\operatorname{Re} \rightarrow 0)$ ときの Neumann の拡散 型表現 (( 8$)$ 式) と Hirt の拡散型表現 ((17) 式と (19) 式）を比較した図を図一 3 に示す。

diagonal diffusion 項のみを考虑した（19）式と Neumann の方法とは一致するのがわかる。拡散型表現 ではごれも $\beta$ に依存しない。 $\gamma$ だけの関数となる。(17) 式の cross diffusion 項を含んだ場合の安定性の条件は 常に（19）式や（8）式よりも緩やかである。

\subsection{Hirt の方法によるタイムステップの決定}

この節では, Neumann の方法によるタイムステップ の Re 依存性について検討する。

図一4に（6.) 式で表される係数（移流型表現 $\operatorname{cof} f_{C N}$ 之拡散型表現 $\left.c o f_{d N}\right)$ の Re 依存性を示す。Re が大き いとき移流型表現（( 7 ) 式）はRe に依存しなくなる。 一方，Reが小さいとき拡散型表現（( 8 ) 式）は Reに 依存しなくなる。Re を大きく(小さく)していったとき, 係数が Re 依存性を示さなくなった Re を critical Re number と言うことにする。係数が拡散型 $\left(c o f_{d N}\right)$ の場 合の critical Re number Re.d で, “係数が移流型 $\left(c_{c o} f_{c N}\right)$ の場合の critical Re number をRe. c で表すこ とにする。図一 4 に示すように, $\beta=0$ の場合は Re. d とRe. c は一致する。このような場合には, Hirt の方法 と Neumann の方法は一致する。 $\beta=0.5$ のとき Re. $d$ とRe. c と一致しない。このような Re の範囲では Hirt の方法は有効でない。タイムステップを過大に見積もっ てしまう。

図一5に critical Re number がパラメータ $(\alpha, \beta, \gamma) に$ よってどのように変化するかを示す。大抵の場合 Re. c とRe. d とが一致しているが, $\gamma=1$ や 0.1 などのとき Re. c とRe. d とが一致しない領域が生じているのがわ かる。このような領域では Hirt の方法を用いてタイム ステップを決定するにはなんらかの補正が必要になる。 以下ではその補正方法について考察する。

図一6に示すように，（6）式の係数に適当な值の係 数 $c o e$ を掛けてやり, $\operatorname{cof} f_{c N}(\mathrm{Re})>\operatorname{coe} \cdot \operatorname{cof} f_{\mathrm{cH}}$ のとき, 係数 $\operatorname{cof} f_{c}$ を $\operatorname{cof} f_{c}=c o e \cdot \operatorname{cof} f_{c H}$ 亡する。係数 $\operatorname{cof} f_{d}$ の 場合も同様。そして, Re. d $\geqq \operatorname{Re} . c$ となるようにして やる。このようにしてやればすべての Re で Hirt の方 法が使用できる。

たとえば図一6において; Re=Re 1 では安定な夕イ ムステップの上限 $\Delta t_{e x}(\operatorname{Re} 1)$ は次式。

$$
\begin{aligned}
\Delta t_{e x}(\operatorname{Re} 1) & =\operatorname{cof}_{c N}(\alpha, \beta, \gamma, \operatorname{Re} 1) \frac{2 \nu}{U^{2}} \\
& =\operatorname{cof}_{d N}(\alpha, \beta, \gamma, \operatorname{Re} 1) \frac{h^{2}}{4 \nu}
\end{aligned}
$$

ここで，上記の補正を用いてやれば，移流型表現での タイムステップ $\Delta t_{c}(\operatorname{Re} 1)$ と拡散型表現でのタイムス テップ $\Delta t_{d}(\operatorname{Re} 1)$ は各タ.次のように書ける。

$$
\begin{aligned}
& \Delta t_{c}(\operatorname{Re} 1)=\operatorname{coe} \cdot \operatorname{cof} \frac{2 \nu}{U^{2}} \\
& \Delta t_{d}(\operatorname{Re} 1)=\operatorname{coe} \cdot \operatorname{cof} \frac{h^{2}}{4 \nu} .
\end{aligned}
$$

3 つのタイムステップの関係は次式となる。

$\Delta t_{d}(\operatorname{Re} 1)<\Delta t_{e x}(\operatorname{Re} 1)<\Delta t_{c}(\operatorname{Re} 1)$
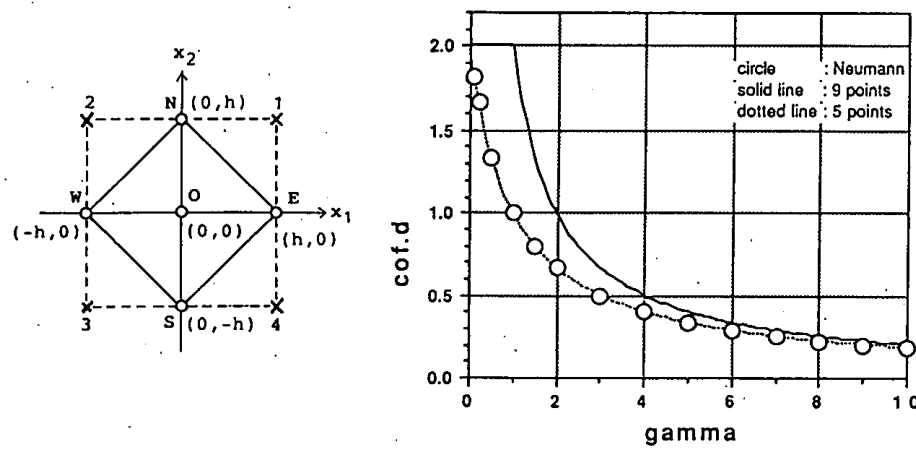

图一2 拡散項の差分点（2 次元）
図一3.2 次元拡散型表現（Hirt と Neumann $の$ 方法の結果)

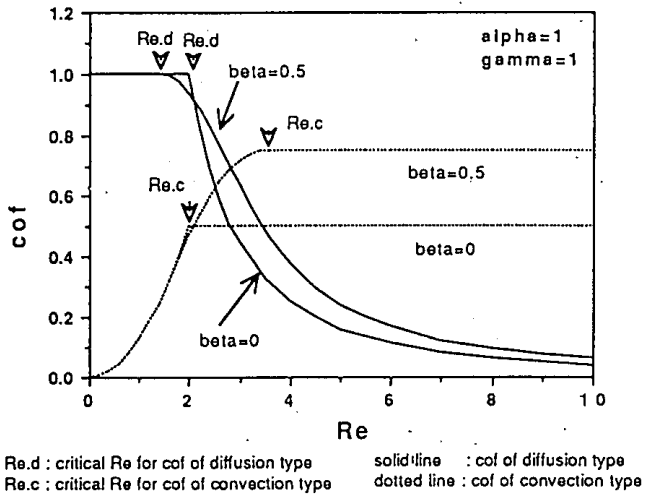

图一4 critical Re number $の$ 位置 


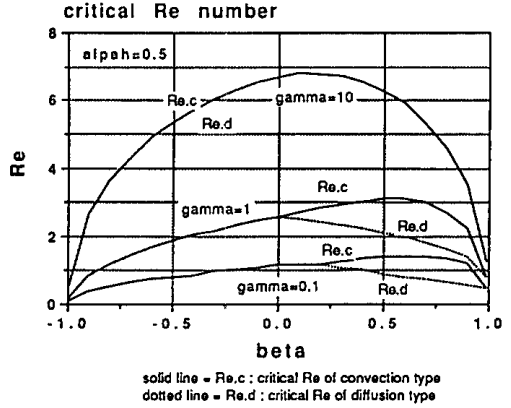

图-5 critical Re number

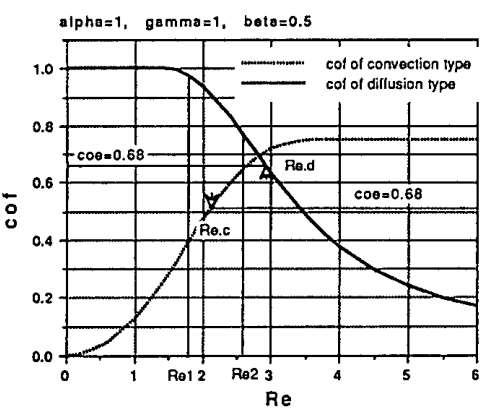

図一6 係数 $c 0 e$ を求める説明図

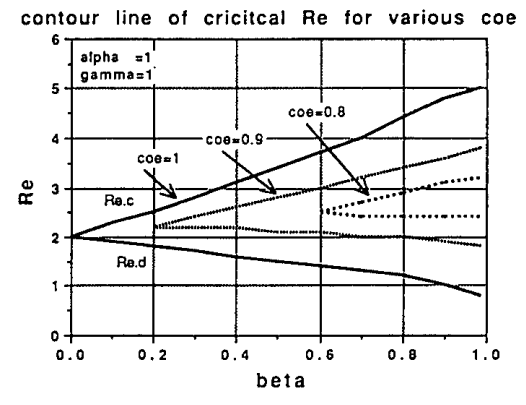

Ra.c: critical Ra number of convection lype

図一7 Re. d とRe. c の等高線
したがって，実際に取るべきタイムステップ $\Delta t$ は次 の関係から決定される。

\section{$\Delta t \leq \min \left\{\Delta t_{d}(\operatorname{Re} 1), \Delta t_{c}(\operatorname{Re} 1)\right\}<\Delta t_{e x}(\operatorname{Re} 1)$}

$\operatorname{Re}=\operatorname{Re} 2$ では, 次の大小関係がなりたつ。

$\Delta t_{d}(\operatorname{Re} 2)<\Delta t_{e x}(\operatorname{Re} 2)$

$\Delta t_{c}(\operatorname{Re} 2)<\Delta t_{\text {ex }}(\operatorname{Re} 2)$

したがって，実際に取るべきタイムステップ $\Delta t$ は次 の関係から決定される。

$\Delta t \leq \min \left\{\Delta t_{d}(\operatorname{Re} 2), \Delta t_{c}(\operatorname{Re} 2)\right\}<\Delta t_{e x}(\operatorname{Re} 2)$

以上で Hirt の方法を使用する場合の補正方法を示し た。次に, 係数 coe の值がどの程度が妥当かを調べる。 図一7にcoe を変化させた場合のRe.d d Re. c のグ ラフを示す。coe $=0.7$ 程度にしておけば，すべての領 域で Re. d $\geqq R e . c$ となり Hirt の方法が使用できる。

以上をまとめると, タイムステップは Hirt の方法か ら次式で得られる。

$$
\begin{aligned}
& \Delta t<\min \left\{\operatorname{coe} \cdot \operatorname{cof} \frac{h^{2}}{4 \nu}, \operatorname{coe} \cdot \operatorname{cof} \frac{2 \nu}{U^{2}}\right\} \\
& \operatorname{cof} \frac{h^{2}}{4 \nu}=\frac{h^{2}}{2\left(\nu_{11}+\nu_{22}\right)} \\
& \operatorname{cof} \frac{2 \nu}{U^{2}}=\frac{2\left[\nu_{11} \nu_{22}-\left(\nu_{12}\right)^{2}\right]}{\nu_{22} U_{1}^{2}+\nu_{11} U_{2}^{2}-2 \nu_{12} U_{1} U_{2}}
\end{aligned}
$$

$\operatorname{Re}<7$ では $c o e=0.7$ 程度, $\operatorname{Re} \geqq 7$ では $c o e=1$ とす ればよい。

\section{3 次元移流拡散方程式の安定性解析}

4.1 Neumann のフーリエ級数法によるタイムステップ の決定

以後の解析のために，粘性と流速を次のように表す。

$$
\begin{aligned}
& U_{1}=U, \quad U_{2}=c_{2} U, \quad U_{3}=c_{3} U \\
& \nu_{11}=\nu, \quad \nu_{22}=\alpha \nu, \quad \nu_{33}=\beta \nu \\
& \nu_{12}=\gamma_{12} \sqrt{\alpha} \nu, \quad \nu_{13}=\gamma_{13} \sqrt{\beta} \nu, \quad \nu_{23}=\gamma_{23} \sqrt{\alpha \beta} \nu
\end{aligned}
$$

ただし，（2）式の粘性マトリックス $[\nu]$ が正定値とな
るため以下の条件を設ける。

$$
\begin{aligned}
& \left|\gamma_{12}\right|<1, \quad\left|\gamma_{13}\right|<1, \quad\left|\gamma_{23}\right|<1 . \\
& |\gamma|=\left|\begin{array}{ccc}
1 & \gamma_{12} & \gamma_{13} \\
\gamma_{12} & 1 & \gamma_{23} \\
\gamma_{13} & \gamma_{23} & 1
\end{array}\right|>0 \ldots \ldots \ldots . . .
\end{aligned}
$$

$\alpha>0, \quad \beta>0, \quad \nu>0$

2 次元の場合と同様に，(1) 式を時間微分に関して 前進差分 (タイムステップ $\Delta t$ ), 空間差分に関して中 心差分（格子幅 $h$ ）を用いた差分方程式を考える。この 差分方程式をフーリ工級数法により安定性解析を行え ば，タイムステップ $\Delta t$ は次式で表される。

$$
\begin{aligned}
& \Delta t<\operatorname{cof}_{c N}\left(c_{2}, c_{3}, \alpha, \beta, \gamma_{12}, \gamma_{13}, \gamma_{23}, \operatorname{Re}\right) \frac{2 \nu}{U^{2}} \\
& =\operatorname{cof}_{d N}\left(c_{2}, c_{3}, \alpha, \beta, \gamma_{12}, \gamma_{13}, \gamma_{23}, \operatorname{Re}\right) \frac{h^{2}}{6 \nu} \cdots . .
\end{aligned}
$$

ただし，

$$
\operatorname{cof}_{c N}=\min _{\substack{1 \theta_{1} 1 \leq \pi \\ i_{2} \mid \leq \pi \\ \theta_{3} \leq \leqslant \pi}}\left\{\frac{2 a\left(\theta_{1}, \theta_{2}, \theta_{3}, \alpha, \beta, \gamma_{12}, \gamma_{13} \gamma_{23}\right)}{\frac{4}{\operatorname{Re}^{2}} a^{2}+b^{2}\left(\theta_{1}, \theta_{2}, \theta_{3}, c_{2}, c_{3}\right)}\right\}
$$

$$
\operatorname{cof}_{d N}=\min _{\substack{\left|\theta_{1}\right| \leq \pi \\ \text { and } \\\left|\theta_{3}\right| \leq \pi}}\left\{\frac{24 a\left(\theta_{1}, \theta_{2}, \theta_{3}, \alpha, \beta, \gamma_{12}, \gamma_{13} \gamma_{23}\right)}{4 a^{2}+\operatorname{Re}^{2} b^{2}\left(\theta_{1}, \theta_{2}, \theta_{3}, c_{2}, c_{3}\right)}\right\}
$$

$a=\left(1-\cos \theta_{1}\right)+\alpha\left(1-\cos \theta_{2}\right)+\beta\left(1-\cos \theta_{3}\right)$

$+\gamma_{12} \sqrt{\alpha} \sin \theta_{1} \sin \theta_{2}+\gamma_{13} \sqrt{\beta} \sin \theta_{1} \sin \theta_{3}$

$+\gamma_{23} \sqrt{\alpha \beta} \sin \theta_{2} \sin \theta_{3}$

$$
b=\sin \theta_{1}+c_{2} \sin \theta_{2}+c_{3} \sin \theta_{3}
$$

2 次元の場合と同様に，(36）式の右辺の表現を拡散 型表現，第 2 項の表現を移流型表現と呼ぶことにする。 係数 (37) と（38）は数値計算で求める。

\subsection{Hirt $の$ 安定性解析}

\subsection{1 移流型表現}

差分方程式の第 1 微分方程式近似は，2 次元の場合と 同様に，(11）式で表される。実行粘性係数 $\nu_{i j}^{e} も （ 12 ）$ 式で表される。ただし，この場合は 3 次元となる。移流 型表現での Hirt の安定性条件は実効粘性マトリックス $\left[\nu^{e}\right]$ が正定值をとることである。タイムステップを求め 
ると次のようになる。

$$
\Delta t_{1}<\frac{2 \nu_{11}}{U_{1}^{2}}
$$

かつ

$$
\Delta t_{2}<\frac{2\left(\nu_{11} \nu_{22}-\nu_{12}^{2}\right)}{\nu_{22} U_{1}^{2}+\nu_{11} U_{2}^{2}-2 \cdot \nu_{12} U_{1} U_{2}}
$$

かつ

$$
\Delta t<\frac{2|\nu|}{A}
$$

ただし，

$$
\begin{aligned}
& |\nu|=\left|\begin{array}{lll}
\nu_{11} & \nu_{12} & \nu_{13} \\
\nu_{12} & \nu_{22} & \nu_{23} \\
\nu_{13} & \nu_{23} & \nu_{33}
\end{array}\right| \\
& A=U_{1}^{2}\left|\begin{array}{ll}
\nu_{22} & \nu_{23} \\
\nu_{23} & \nu_{33}
\end{array}\right|+U_{2}^{2}\left|\begin{array}{ll}
\nu_{11} & : \nu_{13} \\
\nu_{13} & . \nu_{33}
\end{array}\right| \\
& +U_{3}^{2}\left|\begin{array}{ll}
\nu_{11} & \nu_{12} \\
\nu_{12} & \nu_{22}
\end{array}\right|-2 . U_{1} U_{2}\left|\begin{array}{ll}
\nu_{12} & \nu_{23} \\
\nu_{13} & \nu_{33}
\end{array}\right| \\
& -2 U_{2} U_{3}\left|\begin{array}{ll}
\nu_{11} & \nu_{12} \\
\nu_{13} & \nu_{23}
\end{array}\right|-2 U_{1} U_{3}\left|\begin{array}{ll}
\nu_{22} & \nu_{12} \\
\nu_{23} & \nu_{13}
\end{array}\right|
\end{aligned}
$$

(41)～(43) 式を書き直すよ次式のようになる。

$$
\begin{aligned}
& \Delta t_{1}<\operatorname{cof}_{c H}^{(i)} \frac{2 \nu}{U^{2}} \\
& \operatorname{cof}(1)=1 \cdots \cdots \cdots
\end{aligned}
$$

かつ

$$
\begin{aligned}
& \Delta t_{2}<\operatorname{cof}_{\mathrm{cH}}^{(2)} \frac{2 \nu}{U^{2}} \ldots \ldots \ldots \\
& \operatorname{cof}_{\mathrm{CH}}^{(2)}=\frac{1-\gamma_{12}^{2}}{1+t_{1}^{2}-2 \gamma_{12} t_{1}}
\end{aligned}
$$

かつ

$$
\begin{aligned}
& \Delta t<\operatorname{cof}_{C H} \frac{2 \nu}{U^{2}} \\
& c o f_{C H}=\frac{|\gamma|}{f+a t_{1}^{2}+c t_{2}^{2}+2\left(d t_{1}+b t_{1} t_{2}+e t_{2}\right)}
\end{aligned}
$$

ただし，

$$
\begin{aligned}
& a=1-\gamma_{13}^{2} \\
& b=\gamma_{12} \gamma_{13}-\gamma_{23} \\
& c=1-\gamma_{12}^{2} \\
& d=\gamma_{13} \gamma_{23}-\gamma_{12} \\
& e=\gamma_{12} \gamma_{23}-\gamma_{13} \\
& f=1-\gamma_{23}^{2} \text {. }
\end{aligned}
$$

ここで, 係数（49）と（51）はともに正の值をとる ([Appendix-5] 参照)。係数 (47), (49), (51) の大小 関係は次式となる ([Appendix-6]. 参照)。

$$
\operatorname{cof}_{\mathrm{CH}} \leq \operatorname{cof} f_{\mathrm{CH}}^{(2)} \leq \operatorname{cof}(\mathrm{CH}
$$

したがって,タイムステップ $\Delta t$ は(43)あるいは (50) 式で決定される。

Re は十分大きいときの Neumann の移流型表現（(37) 式）とHirt の移流型表現（(51）式）とを比較した図を 図一8に示す。Hirt の方法と Neumann の方法とは, Re が十分大きいとき一致するのがわかる。

\section{2 .2 拡散型表現}

差分方程式の第 1 微分方程式近似は, 2 次元の場合と 同様に，(15）式でも表される。ただし，この場合は 3 次元となる。以下では（15）式下線部の波動方程式を考 察する。. 3 次元の場合の (1) 式の拡散項の差分格子点 を図一9に示す。図一 9 で, ○印は diagonal diffusion 項の差分格子点，×印は cross 項の差分格子点を表す。 cross 項の領域は多面体を構成しない。

diagonal diffusion 項の差分格子点のみが多面体を構 成する。したがって，拡散表現での Hirt の安定性条件 を考えるとき, diagonal diffusion 項のみをとりあげれ ば良いと推定される。diagonal 項のみを考虑した Hirt の安定性条件は次式の様になる ([Appendix-7] 参照)。

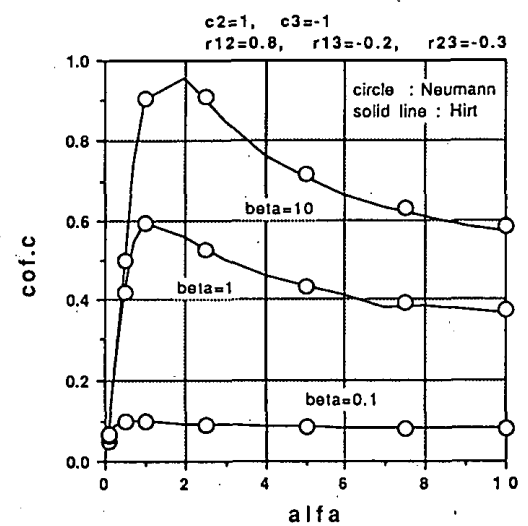

図--8 3 次元移流型表現（Hirt 之 Neumann の方法の結果)

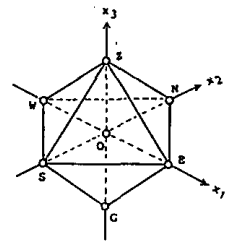

(a)

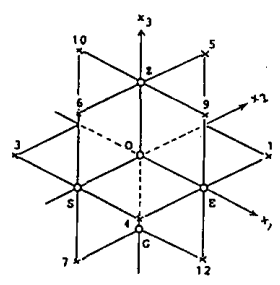

(b)

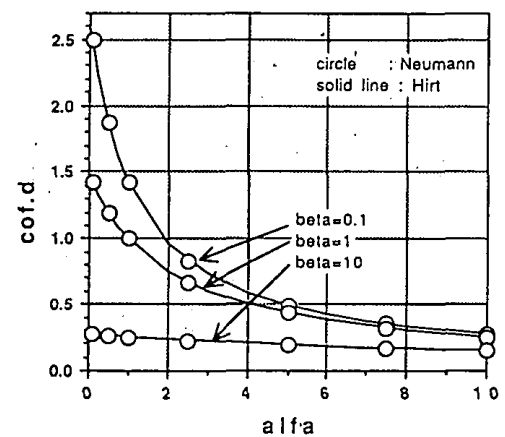

図一10 3 次元拡散型表現 (Hirt と Neumann の方法の結果)

(a) 対角項によって作られる多面体

(b) cross 項によって作られる面 


$$
\Delta t<\frac{1}{\nu_{11}+\nu_{22}+\nu_{33}} \frac{h^{2}}{2}=\operatorname{cof}_{a H} \frac{h^{2}}{6 \nu}
$$

ただし，

$$
\operatorname{cof}_{\mathrm{dH}}=\frac{3}{1+\alpha+\beta}
$$

Re が十分小さいときの Neumann の拡散型表現 ((38) 式）とHirt の拡散型表現（(60) 式）とを比較した図を 図一10に示す。Neumann の方法と Hirt の方法とは一 致する。㹡散型表現においては, Neumannの方法, Hirt の方法ともに $\gamma_{12}, \gamma_{13}, \gamma_{23}$ に依存しない， $\alpha$ と $\beta$ だ けの関数となる。

\section{3 Hirt の方法によるタイムステップの決定}

2 次元の場合と同様に 3 次元の場合にも critical $\operatorname{Re}$ number の Re.dとRe. c とが一致しない領域が存在す る。このような領域では Hirt の方法は有効でない。

2 次元の場合と同様に，Re.d $\geqq \operatorname{Re} . \mathrm{c}$ となるように補 正係数 coe の值を決める必要がある。3 次元の場合に は変化させるパラメータの数が多いため, 2 次元の場合 のように図式的にcoe を決定することは難しい。した がって,この場合には大型計算機を利用することにする。 coe を決定するフローチャートを図一11に示す泣2)。

実際の計算では，Re. $\mathrm{d} \geqq \operatorname{Re} . \mathrm{c}$ の条件は以下の条件 ([条件A] とする) で置き換えた。 [条件A]：

$\operatorname{cof}_{c N}\left(c_{2}, c_{3}, \alpha, \beta, \gamma_{12}, \gamma_{13}, \gamma_{23}, \mathrm{Re}\right)<\operatorname{coe} \cdot \operatorname{cof} f_{c H}$

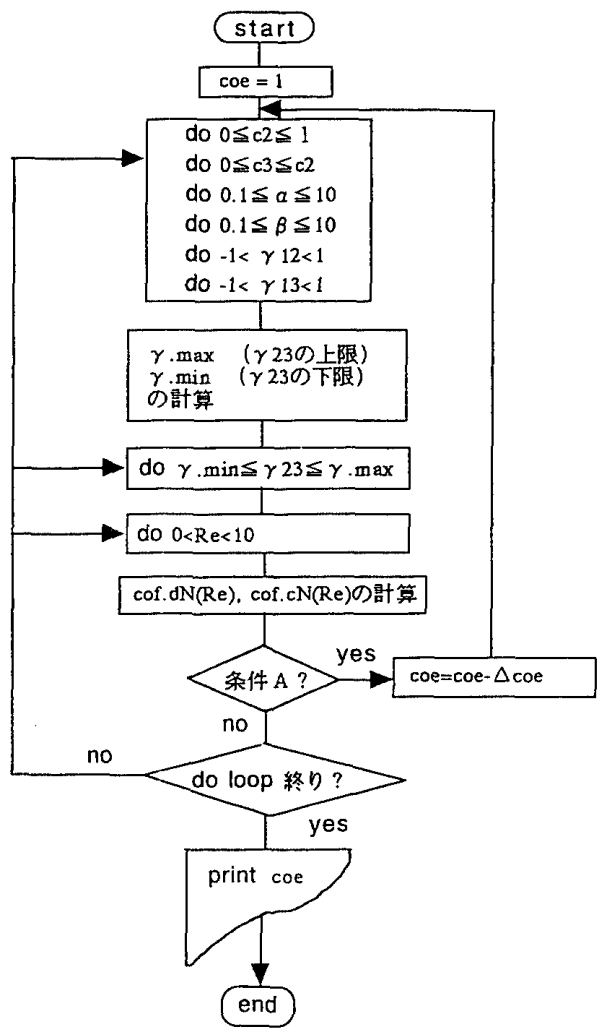

図一11 補正係数 $c o e$ を求めるフローチャート
かつ

$\operatorname{cof}_{\mathrm{dN}}\left(c_{2}, c_{3}, \alpha, \beta, \gamma_{12}, \gamma_{13}, \gamma_{23}, \operatorname{Re}\right)<\operatorname{coe} \cdot \operatorname{cof} f_{\mathrm{dH}}$

上記の条件を満せば，Re. $\mathrm{d}<\operatorname{Re} . \mathrm{c}$ となる。すべて のパラメータで上記の条件を満たさない最大のcoe が 求める coe 值である。計算結果は $c o e=0.6$ となった。

以上をまとめると，3 次元の場合，タイムステップは Hirt の方法から次式で得られる。

$$
\Delta t<\min \left\{\cos e \cdot \operatorname{cof} f_{d H} \frac{h^{2}}{6 \nu}, \cos e \cdot \operatorname{cof} f_{C H} \frac{2 \nu}{U^{2}}\right\}
$$

ただし，

$$
\begin{aligned}
& \operatorname{cof}_{\mathrm{dH}} \frac{h^{2}}{6 \nu}=\frac{h^{2}}{2\left(\nu_{11}+\nu_{22}+\nu_{33}\right)} \\
& \operatorname{cof}_{C H} \frac{2 \nu}{U^{2}}=\frac{2|\nu|}{A}
\end{aligned}
$$

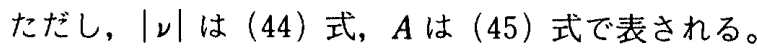
ここで, coe の値は 0.6 程度でよい。

\section{5. 結 論}

（1）cross diffusion 項をもつ移流拡散方程式の安定性 解析では, Hirt の方法と Neumann の方法では必ずしも 一致しない。ただし, cross diffusion 項のない場合には, 2, 3 次元場でも Hirt の方法と Neumann の方法は一致 することが Neumann の方法の数值解から分かる。 cross 項のない場合には, Re. c=Re.dとなるためであ る。

（2）Hirt の安定性解析を用いて cross diffusion 項を もつ移流拡散方程式のタイムステップを決定するには, 2 次元の場合は (28) 式, 3 次元の場合は (64) 式を用 いればよい。補正係数 coe の值は, 2 次元では $0.7,3$ 次元では 0.6 程度とすればよい。

\section{謝 辞}

文献 3）は東大生産技術研究所 村上教授よりいただ いた。記してこここ謝意を表す。

注

1）Hirt の原論文では cross diffusion 項を考慮していない。 前進差分によって生じる cross diffusion 項による安定性 をも考慮していない。実効粘性係数の diagonal diffusion 項のみが正となることを安定性の条件としている。Hirt の結果はNeumann の方法とは一致しない。

2) $c_{2}, c_{3}$ の探索範囲の妥当性は， $\alpha, \beta, \gamma_{12}, \gamma_{13}, \gamma_{23}, \theta_{1}, \theta_{2}$, $\theta_{3}$ の探索範囲加ら理解できる。 $c_{2}<0$ のときは, $\operatorname{cof} f_{d N}$ $\operatorname{cof}_{c N}$ の値は $\gamma_{12}=-\gamma_{12}, \gamma_{23}=-\gamma_{23}, \theta_{2}=-\theta_{2}$ のときと一 致する（条件 (34)，(39)，(40) 式を参照)。 $c_{3} \leqq c_{2}$ の探 索範用は $0.1<\alpha<10,0.1<\beta<10$ のため, どちらか一 方を大きい方にしておけばよい。 


\section{[Appendix-1]}

以下のような 2 階線形偏微分方程式をとりあげる。

$$
\nu_{i} \frac{\partial^{2} \phi}{\partial x_{i} \partial x_{j}}+\Phi(x, \phi, \operatorname{grad} \phi)=0
$$

ここで， $\nu_{i}$ ，は実対称行列で，正定值を取るものとする。行列 [ $\nu$ ] の固有値を $\lambda_{1}, \lambda_{2}, \lambda_{3}$ とする。実対称行列 [ $\left.\nu\right]$ は正定値行列 のため, 固有値はすべて正である4)。

座標軸を回転させる座標変換 $(\{y\}=[\alpha] \mid x\},\{x \mid=[\beta]\{y\},[\beta]=$ $\left.[\alpha]^{-1}=[\alpha]^{t}\right)$ を行う。 $\phi(x(y))=\tilde{\phi}(y)$ と表せば，(ap 1.1）式は

$$
\tilde{\nu}_{i s} \frac{\partial^{2} \tilde{\phi}}{\partial y_{i} \partial y_{J}}+\tilde{\phi}(y, \tilde{\phi}, \operatorname{grad} \tilde{\phi})=0
$$

$$
\text { ここで, }
$$

$$
\tilde{\nu}_{l k}=\nu_{i j} \alpha_{l i} \alpha_{k j}=\beta_{i l} \nu_{l j} \beta_{j k}=\beta_{l i}^{t} \nu_{l j} \beta_{j k}
$$

$[\beta]$ は直交行列であり, 固有値 $\lambda_{1}, \lambda_{2}, \lambda_{3}$ に対応する固有べク卜 ルによって生成される。(ap 1.3) 式をマトリックス形で表せば 次式となる。

$$
[\tilde{\nu}]=[\beta]^{2}[\nu][\beta]=\left[\begin{array}{ccc}
\lambda_{1} & 0 & 0 \\
0 & \lambda_{2} & 0 \\
0 & 0 & \lambda_{3}
\end{array}\right]
$$

したがって, (ap 1.2) 式は以下のように, 正の固有值を拡散 係数とする対角成分のみの 2 階偏微分方程式になる。

$$
\lambda_{J} \frac{\partial^{2} \tilde{\phi}}{\partial y_{j}^{2}}+\tilde{\phi}(y, \tilde{\phi}, \operatorname{grad} \tilde{\phi})=0 .
$$

固有值 $\lambda_{1}, \lambda_{2}, \lambda_{3}$ は正であるから，次のような座標のスケーリ ングを行えば,

$$
z_{1}=\frac{y_{1}}{\sqrt{\lambda_{1}}}, \quad z_{2}=\frac{y_{2}}{\sqrt{\lambda_{2}}}, \quad z_{3}=\frac{y_{3}}{\sqrt{\lambda_{3}}}
$$

(ap 1.1) 式は結局は次のような棈円型の微分方程式になる。

$$
\frac{\partial^{2} \hat{\phi}}{\partial z_{j}^{2}}+\hat{\Phi}(z, \hat{\phi}, \operatorname{grad} \hat{\phi})=0
$$

ここで,

$$
\tilde{\phi}(y(z))=\hat{\phi}(z)
$$

\section{[Appendix-2]}

（15）式下線部の波動方程式を考える。

$$
\frac{\Delta t}{2:} \frac{\partial^{2} \phi}{\partial t^{2}}-\nu_{i j}, \frac{\partial^{2} \phi}{\partial x_{i} \partial x_{j}}=0
$$

[Appendix-1] と同様に座標の回転とスケーリングをおこな えば，(ap 2.1）式は最終的に次のような波動方程式になる。

$$
\frac{\Delta t}{2} \frac{\partial^{2} \hat{\phi}}{\partial t^{2}}-\frac{\partial^{2} \hat{\phi}}{\partial z_{j}^{2}}=0
$$

$$
\text { ここで, }
$$$$
\phi(x(y))=\tilde{\phi}(y(z))=\hat{\phi}(z)
$$

原点 0 を通る (ap 2.2) 式の特性錐 $\mathrm{K}$ は次式で表される。

$$
K: c^{2} t^{2}-z_{j}^{2}=0
$$
ここで,

$$
c=\sqrt{\frac{2}{\Delta t}}
$$

$t=\Delta t$ のとき, 特性錐 $K$ の断面は半径 $r$ の球 $S$ (2 次元の 場合は円）となる。

$$
S: z_{j}^{2}=r^{2}
$$
ここで,

$$
r=c \Delta t=\sqrt{2 \Delta t}
$$

この特性錐 $K$ の断面が差分格子によって作られる多面体の内 部に含まれることが，Hirt の方法による挔散型表現の㚣定性条 件になる。

\section{[Appendix-3]}

2 次元の場合をとりあげる。実対称粘性マトリックス $\left(\nu_{i j}\right)$ を 次式で表す。

$$
[\nu]=\left[\begin{array}{cc}
\nu & \beta \sqrt{\gamma} \nu \\
\beta \sqrt{\gamma} \nu & \gamma_{\nu}
\end{array}\right]
$$

ただし，マトリックス $[\nu]$ は正定値をとるように，以下の条件 を課する。

$$
|\beta|<1, \quad \gamma>0
$$

マトリックス $[\nu]$ の固有値を $\lambda_{1}, \lambda_{2}$ とする。 $\lambda_{i}$ に対する固有 ベクトルを $v^{i}$ とする。(ap 3.1) に対する $\lambda_{i}$ と $v^{i}$ は各々つぎの ようになる。

$$
\begin{aligned}
& \lambda_{1}=\frac{1}{2} \nu\{(1+\gamma)+\sqrt{s}\} \\
& \left.\lambda_{2}=\frac{1}{2} \nu \mid(1+\gamma)-\sqrt{s}\right\} \\
& \boldsymbol{v}^{1}=\left(v_{1}^{1}, v_{2}^{1}\right)=\left(\left[\frac{\sqrt{s}+(1-\gamma)}{2 \sqrt{s}}\right]^{\frac{1}{2}}, \frac{2 \beta \sqrt{\gamma}}{[2 \sqrt{s} \cdot \sqrt{s}+(1-\gamma)\}]^{\frac{1}{2}}}\right) \\
& v^{2}=\left(v_{1}^{2}, v_{2}^{2}\right)=\left(-\left[\frac{\sqrt{s}-(1-\gamma)}{2 \sqrt{s}}\right]^{\frac{1}{2}}, \frac{2 \beta \sqrt{\gamma}}{[2 \sqrt{s} \mid \sqrt{s}-(1-\gamma)\}]^{\frac{1}{2}}}\right)
\end{aligned}
$$

ただし，

$$
s=(1-\gamma)^{2}+4 \beta^{2} \gamma
$$

また, [Appendix-1] で示した座標の回転マトリックス $[\alpha]$ は 固有ベクトルを用いて次式で表される。

$$
[\alpha]=\left[\begin{array}{cc}
v_{1}^{1} & v_{2}^{1} \\
v_{1}^{2} & v_{2}^{2}
\end{array}\right]
$$

$x$ 座標から $z$ 座標への変換式は次式。

$$
\left\{\begin{array}{l}
z_{1} \\
z_{2}
\end{array}\right\}=\left[\begin{array}{ll}
\frac{a_{11}}{\sqrt{\lambda_{1}}} & \frac{a_{12}}{\sqrt{\lambda_{1}}} \\
\frac{a_{21}}{\sqrt{\lambda_{2}}} & \frac{a_{22}}{\sqrt{\lambda_{2}}}
\end{array}\right]\left\{\begin{array}{l}
x_{1} \\
x_{2}
\end{array}\right\}
$$

付図一 1 に示すように, $x$ 座標での点 $1,2,3,4$ で作られる正 方形は， $z$ 座標では平行四辺形に変換される。 $z$ 座標で, 点 3 から点 4 へのベクトルを $A$, 点 3 から点 2 へのベクトルを $B$ と する。 $A$ の長さ $|A|, B$ の長さ $|B|$ は各々次式で表される。

$$
\begin{aligned}
& |A|=2 h \sqrt{\frac{\gamma \nu}{\lambda_{1} \lambda_{2}}} \\
& |B|=2 \stackrel{h}{\frac{\nu}{\lambda_{1} \lambda_{2}}}
\end{aligned}
$$

平行四辺形の面積 $S$ は（ap 3.12）式で表されるため, 距離 $d_{A}, d_{B}$ は次式となる。

$$
S=\frac{4 h^{2}}{\sqrt{\lambda_{1} \lambda_{2}}}
$$
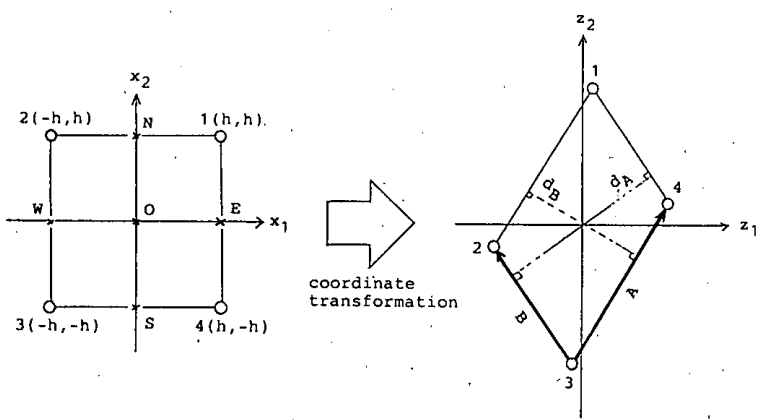

付図一1 座標の回転とスケーリング 


$$
\begin{aligned}
& d_{A}=\frac{2 h}{\sqrt{\nu}} \cdots \cdots \\
& d_{B}=\frac{1}{\sqrt{\gamma}} \frac{2 h}{\sqrt{\nu}}
\end{aligned}
$$

[Appendix-2] から安定性の条件は次式となる。

$$
r<\min \left\{\frac{d_{A}}{2}, \frac{d_{B}}{2}\right\}
$$

上式を書き直すと，最終的に安定性の条件は次式となる。

$$
\begin{aligned}
& \Delta t<\operatorname{cof} f_{d(9) \mathrm{H}} \frac{h^{2}}{4 \nu} \ldots \ldots . . \\
& \operatorname{cof}_{d(9) H}=\min \left\{2, \frac{2}{\gamma}\right\}
\end{aligned}
$$

(ap 3.16)，(ap 3.17）式が, cross diffusion 項の差分格子を 考虑したときの，Hirt の方法による拡散形の安定性条件である。

\section{[Appendix-4]}

diagonal diffusion 項の差分格子点 $\mathrm{E}, \mathrm{N}, \mathrm{W}, \mathrm{S}, \mathrm{O}$ のみを考 虑するときは, [Appendix-3] と異なり座標軸の回転は必要ない。 対角成分の粘性係数での座標のスケーリングのみを行う。付図 一2に示すように, $x$ 座標での正方形 (ENWSE) は $z$ 座標で は菱形になる。この菱形の内部に特性錐の断面（円）が含まれ ることが安定性の条件となる。導出方法は, [Appendix-3] と 同様にすればよい。
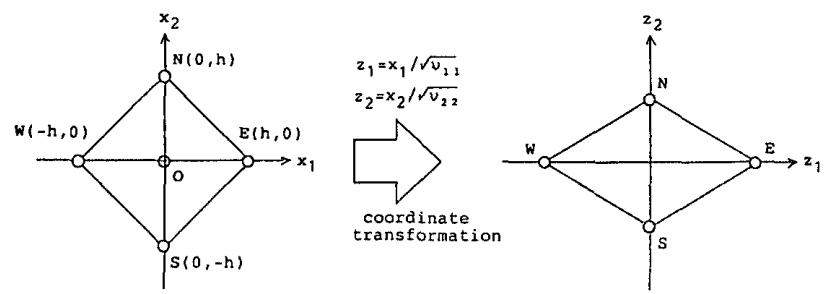

付図一2 坐標のスケーリング

\section{[Appendix-5]}

(1) $\left|\gamma_{12}\right|<1$ から, $\operatorname{cof} f_{c H}^{(2)}>0$ は明らか。

(2) $\operatorname{cof} f_{c H}$ の分子は $|\gamma|>0$ ((34) 式) であるから, $c o f_{C H}$ の分母は正であることを以下に示す。 $\operatorname{cof} f_{c H}$ の分母を $B\left(t_{1}, t_{2}\right)$ で表すと，Bが最小となる $t_{1}, t_{2}$ を $t_{1}^{*}, t_{2}^{*}$ とすると，

$$
\left\{\begin{array}{l}
t_{1}^{*} \\
t_{2}^{*}
\end{array}\right\}=\frac{1}{|\gamma|}\left[\begin{array}{cc}
c & -b \\
-b & a
\end{array}\right]\left\{\begin{array}{l}
-d \\
-e
\end{array}\right\}=\left\{\begin{array}{l}
\gamma_{12} \\
\gamma_{13}
\end{array}\right\}
$$

ここで，以下の関係を用いた。

$$
\begin{aligned}
& a c-b^{2}=|\gamma| \ldots \ldots \\
& b e-c d=\gamma_{12}|\gamma| \\
& b d-a e=\gamma_{13}|\gamma|
\end{aligned}
$$

したがって, $B\left(t_{1}^{*}, t_{2}^{*}\right)=B\left(\gamma_{12}, \gamma_{13}\right)=|\gamma|>0$ となり, $\operatorname{cof} f_{\text {cH }}$ は正 である。

\section{[Appendix-6]}

(1) $\left|\gamma_{12}\right|<1$ から, $\operatorname{cof}(2) \leqq c o f_{c H}^{(1)}$ 时明らか。

(2) 以下では, $\operatorname{cof} f_{c H} \leqq c o f_{c H}^{(2)}$ を証明する。 $\operatorname{cof} f_{c H}, c o f_{c H}^{(2)}$ の分母，分子はすべて正であるため，

$$
\begin{aligned}
& \text { ( } \left.\operatorname{cof}_{c H} \text { の分子 }\right) \times\left(\operatorname{cof}_{c H}^{(2)} \text { の分母 }\right)-(\operatorname{cof} c H \text { の分母 }) \\
& \times\left(\operatorname{cof}_{c H}^{(2)} \text { の分子 }\right) \geqq 0
\end{aligned}
$$

を証明すれば良い。(ap 5.2) と（ap 5.3）の関係式と $f_{\mathrm{c}}-$ $|\gamma|=e^{2}$ の関係を用いると, (ap 6.1) を証明するには,

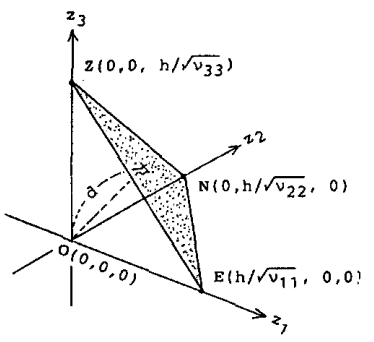

付図一3 $z$ 座標での原点から多面体への距離

$$
b^{2} t_{1}^{2}+2 b e t_{1}+c^{2} t_{2}^{2}+2 b c t_{1} t_{2}+2 c e t_{2}+e^{2} \geq 0
$$

を証明すればよい。

(ap 6.2) 左辺が最小となる $t_{1}, t_{2}$ を $t_{1}^{*}, t_{2}^{*}$ とすると,

$$
t_{1}^{*}=t_{2}^{*}=-\frac{e}{b+c} \cdots \cdots \cdots \cdots \cdots \cdots \cdots \cdots \cdots \cdots \cdots \cdots \cdots \cdots \cdots \cdots \cdots \cdots \cdots \cdots(\text { ap } 6.3)
$$

上式を（ap 6.2）左辺に代入すると（ap 6.2）左辺二0となる。 したがって， $\operatorname{cof} f_{C H} \leqq \operatorname{cof}$ CH $_{\text {(2) }}$ は常に満たされる。

\section{[Appendix-7]}

2 次元の [Appendix-2] と同様に，以下のように対角成分の 粘性係数で座標のスケーリングを行う。

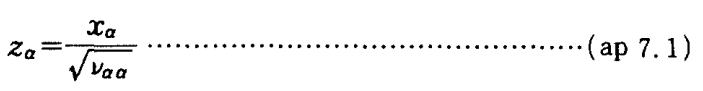

$$
\begin{aligned}
& \text { ( } \alpha \text { : no summation, } \alpha=1,2,3 \text { ) }
\end{aligned}
$$

波動方程式（ap 2.2）の特性錐の断面は，(ap 2.6）で表され る半径 $r$ の球となる。付図一 3 より, 拡散表現での Hirt の安定 性条件は次式となる。

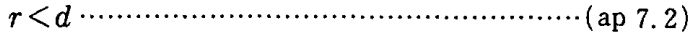

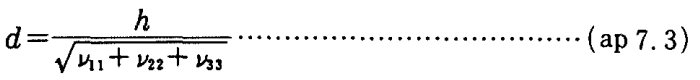

したがって，(ap 2.7）を考慮すると（ap 7.2）は（60）式と なる。

\section{参考文献}

1) Hirt, C.W. : Heuristic stability theory for finitedifference equations, J. Computational Physics, Vol.2, pp. $339 \sim 355,1968$

2) Huang, P. G. and Leschziner, M. A. : Stabilization of recirculating-flow compuations performed with secondmoment closures and third-order discretization, 5th Symposium on Turbulent Shear Flows, pp. 20. 7 20. 12, 1985

3) Launder, B. E. : Second-moment closure, methodology and practice. Univ. Manchester Institute of Sci. and Tech. Rep., No. TFD/82/4, 1983

4) 佐武一郎: 行列亡行列式, 裳華房

5) 平岡久司, 中村素人：MAC 法による応力方程式モデル の解法, 日本建築学会計画系論文報告集, 第 431 号, pp. 1 10, 1992

6）矢鴄信男, 野木達夫：発展方程式の数値解析, 岩波書店, 1977

7) ローチェ：コンピュータによる流体力学, 構造解析研究 所

(1992 年 5 月 25 日原稿受理, 1992 年 9 月 30 日採用决定) 